\title{
A comparison of epidermal growth factor receptor mutation testing methods in different tissue types in non-small cell lung cancer
}

\author{
SUQIN YI ${ }^{1}$, YUAN ZHUANG $^{1}$, JUN ZHOU $^{1}$, HAITAO MA $^{2}$, JIANAN HUANG $^{3}$, LIN WANG $^{4}$, \\ WEIDONG ZHU ${ }^{5}$, SUYA KANG ${ }^{5}$, LINCHUAN GUO ${ }^{5}$ and FENG GUO ${ }^{1}$ \\ ${ }^{1}$ Central Laboratory and Departments of ${ }^{2}$ Cardiothoracic Surgery, ${ }^{3}$ Respiratory Medicine, ${ }^{4}$ Special Requirements Ward, \\ and ${ }^{5}$ Pathology, The First Affiliated Hospital of Soochow University, Suzhou 215006, P.R. China
}

Received February 11, 2014; Accepted May 12, 2014

DOI: $10.3892 /$ ijmm.2014.1789

\begin{abstract}
The detection of somatic epidermal growth factor receptor $(E G F R)$ mutations is valuable when an appropriate therapy, either EGFR-tyrosine kinase inhibitor (TKI) therapy or chemotherapy, for patients with advanced non-small cell lung cancer (NSCLC) needs to be selected. Although it is well-understood that EGFR mutation detection is significant for the decision-making regarding treatment, no consensus on the methodology that should be the most preferebale for detecting mutations in clinical practice has been reached. The presence of false positives due to the technique carried out for mutation analysis affects the accurate estimation of response EGFR-TKI therapy. Furthermore, false negatives directly exclude the potential application of an EGFR-TKI. In the present study, we present the results of detecting EGFR mutations in individual sample types using three different low- or high-sensitivity techniques. We suggest that the choice of the method used should be made based on the type of the sample. Our results revealed that EGFR mutations were less frequently detected in bronchoscopic biopsies, regardless of the method used. However, the amplification refractory mutation system (ARMS) was optimal owing to the small amount of DNA prepared for biopsy. The cytology sample was a valuable alternative to traditional samples, given that a sensitive method for detecting mutations was used. For surgical resections, the testing method may be selected based on the expertise of each laboratory, but direct sequencing is highly recommended. We also suggest that two methods should be used sequentially (the screening and targeted methods) in clinical practice due to the presence of non-neglected discordance between any method from its own benefits and drawbacks.
\end{abstract}

Correspondence to: Dr Feng Guo, Central Laboratory, The First Affiliated Hospital of Soochow University, 188 Shizi Road, Suzhou 215006, P.R. China

E-mail: guofeng27@suda.edu.cn

Key words: epidermal growth factor receptor mutations, tissue types, methodologies, discordance

\section{Introduction}

In the latest guidelines by the National Comprehensive Cancer Network (NCCN), epidermal growth factor receptor (EGFR)-tyrosine kinase inhibitor (TKI) is recommended as first-line therapy for patients with advanced non-small cell lung cancer (NSCLC) harboring activating EGFR mutations.

EGFR mutations occur more frequently in patients of Asian ethnicity, females, individuals with no smoking history, and in patients diagnosed with adenocarcinoma. Treatment with EGFR-TKI manifests the greatest efficacy in these patients, with no smoking history being the best predictor of good response to TKI. Mutations are associated with an enhanced sensitivity to an EGFR-TKI located in EGFR exons 18-21, which encode the tyrosine kinase domain. In-frame deletions in exon 19 and a point mutation in exon 21 (p.L858R) are the most prevalent EGFR mutations. Mutations associated with resistance to TKI include a point mutation (p.T790M) and insertions (e.g., p.D770_N771insNPG) in exon 20, and a point mutation (p.D761Y) in exon 19 (1-3).

Although the clinical relevance of activating EGFR mutations with TKI response in advanced NSCLC is well-addressed, a standardized and commonly accepted approach in terms of optimal sensitivity, specificity, reproducibility and accuracy in detecting EGFR mutations has not been adopted to date (4-6). A variety of techniques for mutation analysis of the EGFR gene exist. These are classified into screening methods that identify all mutations and targeted methods that distinctively detect known and pre-determined mutations.

Among diverse screening methods, the direct sequencing of polymerase chain reaction (PCR) products is still widely used, despite its low sensitivity. Direct sequencing does not require sample batching, while it provides better contamination control since the exact, specific mutation is presented. However, direct sequencing is time-consuming and successful only when viable tumor cells constitute at least $25 \%$ of the tissues $(7,8)$. Alternative screening methods include high resolution melting (HRM), pyrosequencing and denaturing high pressure liquid chromatography (dHPLC) analysis. HRM is an in-tube, fast method that detects sequence variation by 
monitoring the melting curve of PCR amplicons. HRM is able to detect mutant genes at levels of 1-10\% (9-11). Nevertheless, the requirement for sequencing validation increases the turnaround time and reduces the value of high sensitivity.

The limited sensitivity of conventional sequencing necessitates the adoption of more sensitive approaches. Scorpion amplification refractory mutation system (ARMS) falls into the targeting method category and has been successfully used to analyze the EGFR mutation status in the phase III Iressa Pan-Asia Study (IPASS) clinical trial (12). ARMS detects mutations in samples with a mutation frequency as low as 0.1 to $1 \%$, but detects known mutations only. Additionally, ARMS requires the batching of samples and the reagents required are expensive.

Samples used for analyzing EGFR mutations differ between laboratories. Samples can be obtained either at the stage of diagnosis (biopsy) or at the stage of surgical intervention (resections). Large samples from surgical intervention are preferred, but small biopsy samples are also regularly used. Unfortunately, tissue samples are not always available; therefore, cytological materials, including pleural effusion, bronchial scraping and bronchofiberscopic brushing are being increasingly used. In fact, the mutation detection rate achieved with cytologyical material is comparable with that achieved with tissue samples obtained by biopsy or resection (5).

In the present study, we analyzed the EGFR mutation status of 356 patients with advanced NSCLC and systemically compared the mutation detection rate of direct sequencing, the gold standard, with more sensitive methods, i.e., ARMS and HRM, in different tissue types. The overall mutation rate of the EGFR gene was $44.10 \%$ and the rate of activating EGFR mutations was $39.04 \%$. The activating EGFR mutations occurred more frequently in females and patients diagnosed with adenocarcinoma. The EGFR mutation frequency identified from the bronchoscopic biopsies was lower than that from surgical resections, regardless of the method used. The mutation rate detected from the cytological sample was similar to that achieved with surgical resections and a sensitive method for detecting mutations in the cytological samples was required. Each method has advantages and disadvantages; it was thus suggested that the choice of method in clinical practice should be made based on the sample type. ARMS was recommended when mutations were detected in bronchoscopic biopsies and cytological samples. Direct sequencing was recommended when mutations were identified in surgical resections. However, the lack of $E G F R$ mutations tested by direct sequencing is possibly due to the limited sensitivity of the method. The absence of EGFR mutations, determined by methods that detect known mutations, such as ARMS, cannot be the exclusion criterion for TKI treatment. To reduce false positives and false negatives caused by the limitations of each method, the combination of direct sequencing and a more sensitive technique, such as ARMS, is recommended for identifying EGFR mutations in clinical practice.

\section{Patients and methods}

Subjects. This study was approved by the Institutional Review Board, where samples were collected from and analyzed (the First Affiliated Hospital of Soochow University, Suzhou, China). A total of 356 patients diagnosed with NSCLC were included in the study. The pleural effusion cytological samples were collected from patients diagnosed with NSCLC and confirmed by a pathologist to contain tumor cells.

Sensitivity determination. Two lung cancer cell lines, PC-9 and A549, were used. The A549 cell line was purchased from the Shanghai Institute for Biological Sciences (Shanghai, China). PC-9 cells harbor in-frame deletions in exon 19 of the EGFR gene (heterozygous for c.2235_2249del15). A549 cells are wild-type for the EGFR gene. Serial dilutions of the $E G F R$ mutant PC-9 cells with A549 cells were used to determine the sensitivity of direct sequencing, ARMS and HRM.

Genomic DNA ( $g D N A)$ extraction. Before the extraction of gDNA, representative formalin-fixed, paraffin-embedded (FFPE) sections were stained with hematoxylin and eosin (H\&E) and diagnosed by pathologists. At least $20 \%$ of tumor cells was observed in the FFPE sections. DNA extraction was performed usng the QIAamp ${ }^{\mathrm{TM}}$ DNA FFPE Tissue kit (Qiagen, Shanghai, China) according to the manufacturer's instructions. To obtain DNA fromthe cell lines, the cells were harvested by trypsinization when grown to confluence. To obtain DNA from pleural effusion, the cells were collected by centrifugation. DNA was extracted using gDNA isolation kits (Omega BioTek Guangzhou, Ltd., Guangzhou, China) according to the manufacturer's instructions. DNA was quantified using a NanoDrop ND-1000 fluorospectrometer (ThermoFisher Scientific, Shanghai, China), and the A260/280 value was ensured between 1.8-2.0.

Direct sequencing. Mutation screening of EGFR exons 18-21 was carried out by PCR amplification as previously described (13). The primers for PCR amplification were as follows: $E G F R$ exon 18 forward, GCATGGTGAGGGCTGAGGTGAC and reverse, TATACAGCTTGCAAGGACT CTG; exon 19 forward, GTGCATCGCTGGTAACATCCA and reverse, GGAGAT GAGCAGGGTCTAGAGCA; exon 20 forward, GATCGC ATTCATGCGTCTTCACC and reverse, TTGCTATCCCAGG AGCGCAGACC; exon 21 forward, TCAGAGCCTGGCAT GAACATGACCCTG and reverse, GGTCCCTGGTGTCAGG AAAATGCTGG. PCR reaction was amplified using Platinum Taq DNA polymerase (Invitrogen, Beijing, China) and conducted under the following conditions: $94^{\circ} \mathrm{C} 5 \mathrm{~min},\left(94^{\circ} \mathrm{C}, 30 \mathrm{sec}\right.$, $\left.60^{\circ} \mathrm{C}, 30 \mathrm{sec}, 72^{\circ} \mathrm{C}, 45 \mathrm{sec}\right) \times 40$ cycles, $72^{\circ} \mathrm{C} 10 \mathrm{~min}$. The PCR products were checked on $2 \%$ agarose gels. PCR products were purified and followed by bi-directional sequencing using an ABI 3730 DNA analyzer (Applied Biosystems, Inc., Beijing, China). Sequencing chromatograms were analyzed using DNA Baser 3.0. Nucleotide changes detected by sequencing were all checked in Sanger's COSMIC database (http://cancer.sanger. ac.uk/cosmic/gene/analysis?ln=EGFR\#histo), and diagnosed as mutations accordingly.

ARMS assay. The presence of EGFR mutations was determined using the AmoyDx ${ }^{\mathrm{TM}}$ EGFR 29 Mutations Detection kit, (Amoy Diagnostics Co., Ltd., Xiamen, China). The kit, which has been approved for clinical use by the State Food and Drug Administration (SFDA) in China, detects the most commonly reported 29 somatic mutations (both activating and TKI resistance-related) in the EGFR gene: 19 deletions in exon 19, 
three insertions in exon 20 and point mutations p.G719X (exon 18), p.S768I and p.T790 M (exon 20), p.L858R and p.L861Q (exon 21). The test detects the presence of these mutations, but does not distinguish between them. The analysis was performed according to the manufacturer's instructions using a LightCycler 480 (Roche Diagnostic, Ltd., Shanghai, China).

$H R M$ assay. HRM assay was performed using an EGFR gene mutation detection kit, detecting mutations in EGFR exons 18-21 (Suzhou MicroDiag Biomedicine Co., Suzhou, China) on a LightCycler 480. The melting profiles of the amplicons were analyzed using gene scanning software to detect wild-type and mutations. To affirm the gene scanning results, the amplicons were sequenced after HRM assay.

Statistical analysis. The association of the mutation status of the EGFR gene with any of the clinicopathological characeristics was evaluated. Frequencies were compared using two-tailed Pearson's Chi-square or Fisher's exact test. The difference was considered significant when the $\mathrm{P}$-value was $\mathrm{P}<0.05$. Analyses were performed using the GraphPad Prism 5 program.

\section{Results}

Patient characteristics. A total of 356 samples (from August 2010 to December 2012) were collected and successfully evaluated for $E G F R$ mutations. The clinical characteristics of the patients, such as age, gender, smoking history and pathological evaluation, are summarized in Table I. A total of 210 patients $(58.99 \%)$ were male and $146(41.01 \%)$ were female, with a median age of 57.5 years (range, 27-88 years). Of these patients, $162(45.51 \%)$ were current smokers, 173 (48.60\%) were non-smokers, and 21 (5.89\%) had an unknown smoking history. All samples were confirmed to contain malignant cells and the pathological and cytological diagnosis revealed that $173(48.60 \%)$ of the samples contained adenocarcinoma cells, $56(15.73 \%)$ contained squamous cell carcinoma cells and $127(35.67 \%)$ contained other types of carcinoma cells.

EGFR mutations status. The presence of mutations in EGFR exons 18-21 was analyzed, and the overall mutation rate was $44.10 \%$ (157/356). The mutation frequencies in the males and females were 37.61 (79/210) and 53.42\% (78/146), respectively. There was a significant difference $(\mathrm{P}=0.0034)$ between males and females as regards the EGFR mutation frequency (Table II).

The EGFR mutations detected were further classified into three types, i.e., activating (TKI-sensitive) mutations, TKI-resistant mutations and mutations that were not associated with TKI response. The frequencies of the three types of mutations were 88.54 (139/157), 3.18 (5/157) and 8.28\% (13/157), respectively.

The activating EGFR mutations most frequently occurred in exon 19 , comprising $57.56 \%$ (80/139) of all the activating mutations, followed by $35.25 \%$ (49/139) point mutations in exon 21 (p.L858R and p.L861Q). Ten types of deletion/ insertion in exon 19 detected in the study are summarized in Table III. Of note, three patients harboring specific mutations of p.H835L and p.H838V in EGFR exon 21 were detected. Four patients $(2.87 \%, 4 / 139)$ with a point mutation (p.G719S
Table I. Clinical characteristics of the lung cancer patients.

\begin{tabular}{lcc}
\hline Characteristics & $\begin{array}{c}\text { No. of patients } \\
\text { (total, 356) }\end{array}$ & $\begin{array}{c}\text { Frequency } \\
(\%)\end{array}$ \\
\hline Age (years) & & \\
Median (range) & $57.5(27-88)$ & 54.77 \\
$>60$ & 195 & 45.23 \\
$\leq 60$ & 161 & \\
Gender & & 58.99 \\
Male & 210 & 41.01 \\
Female & 146 & \\
Smoking history & & 45.51 \\
Current smoker & 162 & 48.60 \\
Non-smoker & 173 & 5.89 \\
Unknown & 21 & \\
Histological subtype & & 48.60 \\
Adenocarcinoma & 173 & 15.73 \\
Squamous & 56 & 35.67 \\
Other & 127 &
\end{tabular}

Table II. Mutation rates between male and female NSCLC patients.

\begin{tabular}{lcccc}
\hline Gender & $\begin{array}{c}\text { All } \\
\mathrm{n}(\%)\end{array}$ & $\begin{array}{c}\text { Wild-type } \\
\mathrm{n}(\%)\end{array}$ & $\begin{array}{c}\text { Mutation } \\
\mathrm{n}(\%)\end{array}$ & P-value \\
\hline Male & $210(58.99)$ & $131(65.83)$ & $79(50.32)$ & $0.0034^{\mathrm{a}}$ \\
Female & $146(41.01)$ & $68(34.17)$ & $78(49.68)$ & \\
\hline
\end{tabular}

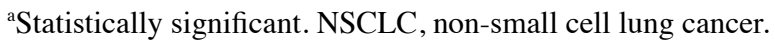

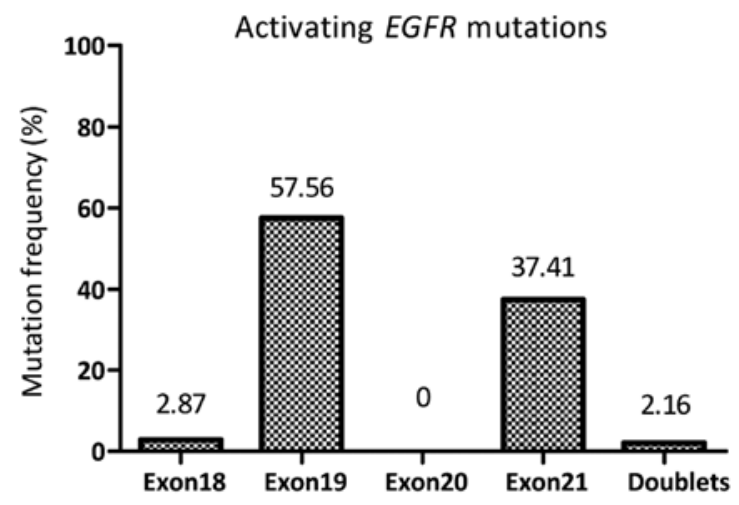

Figure 1. Bar chat showing the distribution of activating mutations in exons 18-21. EGFR, epidermal growth factor receptor.

or p.G719A) in exon 18 and three patients $(2.16 \%, 3 / 139)$ with double mutations in exons 19 and 21 (p.E746_A750del \& p.L858R) were found as activating EGFR mutations (Fig. 1 and Table III).

Five TKI-resistant mutations, including p.T790M, p.D770_ N771insG, p.H773_V774insPH, p.V774_C775insPR, and double mutations in exons 20 and 21 (p.T790M and p.L858R) were detected. In addition, 13 EGFR mutations, which did 
Table III. Molecular characteristics of the 157 NSCLC patients with EGFR mutations.

\begin{tabular}{|c|c|c|c|c|c|}
\hline Exon & $\begin{array}{l}\text { Mutation } \\
\text { type }\end{array}$ & $\begin{array}{c}\text { Nucleotide } \\
\text { change }\end{array}$ & $\begin{array}{l}\text { Amino acid } \\
\text { change }\end{array}$ & No. & $\begin{array}{c}\text { TKI } \\
\text { response }\end{array}$ \\
\hline \multirow[t]{4}{*}{18} & \multirow[t]{3}{*}{ Missense } & c. $2152 \_2153 \mathrm{CT}>\mathrm{TA}$ & L718* & 1 & $\mathrm{U}$ \\
\hline & & c. $2155 \mathrm{G}>\mathrm{A}$ & p.G719S & 2 & $\mathrm{~S}$ \\
\hline & & c. $2156 \mathrm{G}>\mathrm{C}$ & p.G719A & 2 & $\mathrm{~S}$ \\
\hline & Deletion/insertion & c.2127_2129delAAC & p.E709_T710del & 1 & $\mathrm{U}$ \\
\hline \multirow[t]{14}{*}{19} & \multirow[t]{4}{*}{ Missense } & c. $2186 \mathrm{G}>\mathrm{A}$ & p.G729E & 1 & $\mathrm{U}$ \\
\hline & & c. $2227 \mathrm{G}>\mathrm{A}$ & p.A743T & 1 & $\mathrm{U}$ \\
\hline & & c.2239_2240TT>CC & p.L747P & 1 & $\mathrm{U}$ \\
\hline & & c. $2255 \mathrm{C}>\mathrm{T}$ & p.S752F & 1 & $\mathrm{U}$ \\
\hline & \multirow[t]{10}{*}{ Deletion/insertion } & c.2235_2249del15 & p.E746_A750del & 56 & $\mathrm{~S}$ \\
\hline & & c.2236_2250del15 & p.E746_A750del & 13 & $\mathrm{~S}$ \\
\hline & & c.2237_2253del17insTTGCT & p.E746_T751delinsVA & 1 & $\mathrm{~S}$ \\
\hline & & c.2237_2255del19insT & p.E746_S752delinsV & 1 & $\mathrm{~S}$ \\
\hline & & c.2238_2248del11insGC & p.E746_A750delinsEP & 1 & $\mathrm{~S}$ \\
\hline & & c.2239_2250del12insCCG & P.L747_A750delinsP & 1 & $\mathrm{~S}$ \\
\hline & & c.2239_2248del10insC & p.L747_A750delinsP & 1 & $\mathrm{~S}$ \\
\hline & & c.2240_2248del9 & p.L747_A750del & 1 & $\mathrm{~S}$ \\
\hline & & c.2240_2254del15 & p.L747_T751del & 2 & $\mathrm{~S}$ \\
\hline & & c.2240_2257del18 & p.L747_T753del & 3 & $\mathrm{~S}$ \\
\hline \multirow[t]{6}{*}{20} & \multirow[t]{3}{*}{ Missense } & c. $2230 \mathrm{~T}>\mathrm{A}$ & p.L777Q & 1 & $\mathrm{U}$ \\
\hline & & c.2345_2346CT>AA & p.L782N & 1 & $\mathrm{U}$ \\
\hline & & c. $2369 \mathrm{C}>\mathrm{T}$ & p.T790M & 1 & $\mathrm{R}$ \\
\hline & \multirow[t]{3}{*}{ Deletion/insertion } & c.2310_2311insGGT & p.D770_N771insG & 1 & $\mathrm{R}$ \\
\hline & & c.2319_2320insCCCCAC & p.H773_V774insPH & 1 & $\mathrm{R}$ \\
\hline & & c.2322_2323insCCACGT & p.V774_C775insPR & 1 & $\mathrm{R}$ \\
\hline \multirow[t]{8}{*}{21} & \multirow[t]{8}{*}{ Missense } & c. $2483 \mathrm{~T}>\mathrm{A}$ & p.L828* & 1 & $\mathrm{U}$ \\
\hline & & c. $2506 \mathrm{C}>\mathrm{A}$ & p.R836S & 1 & $\mathrm{U}$ \\
\hline & & c. $2573 \mathrm{~T}>\mathrm{G}$ & p.L858R & 46 & $\mathrm{~S}$ \\
\hline & & c. $2582 \mathrm{~T}>\mathrm{A}$ & p.L861Q & 3 & $\mathrm{~S}$ \\
\hline & & c. $2591 \mathrm{C}>\mathrm{A}$ & p.A864E & 1 & $\mathrm{U}$ \\
\hline & & c. $2597 \mathrm{~A}>\mathrm{T}$ & p.E866V & 1 & $\mathrm{U}$ \\
\hline & & c. $2602 \mathrm{G}>\mathrm{A}$ & p.E868K & 1 & $\mathrm{U}$ \\
\hline & & c. $2497 \mathrm{~T}>\mathrm{G} \&$ c $.2504 \mathrm{~A}>\mathrm{T}$ & p.H838V and p.H835L & 3 & $\mathrm{~S}$ \\
\hline \multirow[t]{4}{*}{ Doublets } & & c.2235_2249del15 & p.E746_A750del & 3 & $\mathrm{~S}$ \\
\hline & & c. $2573 \mathrm{~T}>\mathrm{G}$ & p.L858R & & \\
\hline & & c.2235_2249del15 & p.E746_A750del & 1 & $\mathrm{R}$ \\
\hline & & c. $2615 \mathrm{G}>\mathrm{T}$ & p.T790M & & \\
\hline
\end{tabular}

EGFR, epidermal growth factor receptor; NSCLC, non-small cell lung cancer. S, TKI-sensitive; R, TKI-resistant; U, unknown.

not correlate with TKI response, are listed in Table III. These were L718* and p.E709_T710del in exon 18, point mutations (p.G729E, p.A743T, p.L747P and p.S752F) in exon 19, point mutations (p.L777Q and p.L782N) in exon 20, and point mutations (p.L828*, p.R836S, p.A864E, p.E866V and p.E868K) in exon 21.

Correlation between EGFR mutation status and smoking history. Among the 210 male patients, 162 were current smokers, 27 were non-smokers, and 21 had an uknown smoking history (Tables I and IV). All 146 female patients were non-smokers. Overall, the rate of EGFR mutations was significantly decreased in the smokers $(38.27 \%, 62 / 162)$ compared with the non-smokers $(50.87 \%, 88 / 173, \mathrm{P}=0.0141)$. The mutation rate was significantly higher in the female nonsmokers than in the male smokers $(53.42 \%, 78 / 146$ vs. $38.27 \%$, $62 / 162, \mathrm{P}=0.0085)$. Among the non-smokers, the $E G F R$ mutation rates were comparable in the male and female patients (53.42\%, 78/146 vs. $37.04 \%, 10 / 27, \mathrm{P}=0.1439)$. Among the male patients, no statistically significant difference was observed in the non-smokers, smokers and patients with an unknown smoking history $(37.04 \%, 38.27 \%$ and $33.33 \%$; Table IV). 
Table IV. Mutation rates between smokers and non-smokers.

\begin{tabular}{|c|c|c|c|c|}
\hline & $\begin{array}{c}\text { All } \\
\mathrm{n}(\%)\end{array}$ & $\begin{array}{c}\text { Wild-type } \\
\text { n (\%) }\end{array}$ & $\begin{array}{c}\text { Mutation } \\
\mathrm{n}(\%)\end{array}$ & $\mathrm{P}$-value \\
\hline Non-smoker & $173(48.60)$ & $88(56.05)$ & $85(42.71)$ & $0.0141^{\mathrm{a}}$ \\
\hline Males & 27 (7.59) & 17 (8.54) & $10(6.37)$ & \\
\hline Females & $146(41.01)$ & $68(34.17)$ & 78 (49.68) & \\
\hline Smoker & $162(45.51)$ & $62(39.49)$ & $100(50.25)$ & \\
\hline Males & $162(45.51)$ & $100(50.25)$ & $62(39.49)$ & \\
\hline Females & 0 & 0 & 0 & \\
\hline Unknown & $21 \quad(5.89)$ & $7 \quad(4.46)$ & $14(7.04)$ & \\
\hline Males & $21 \quad(5.89)$ & $14(7.04)$ & 7 (4.46) & \\
\hline Females & 0 & 0 & 0 & \\
\hline
\end{tabular}

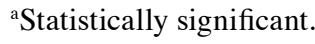

Table V. Association of activating mutation rates with histological subtypes of NSCLC.

\begin{tabular}{lrrrr}
\hline $\begin{array}{l}\text { Histological } \\
\text { subtype }\end{array}$ & Total & $\begin{array}{c}\text { Frequency } \\
(\%)\end{array}$ & $\begin{array}{c}\text { Mutation } \\
\text { rate }(\%)\end{array}$ & Mutation \\
\hline Adenocarcinoma & 173 & 48.60 & 88 & 50.87 \\
$\begin{array}{l}\text { Squamous cell } \\
\text { Large cell }\end{array}$ & 56 & 15.73 & 14 & 25.00 \\
Adenosquamous & 11 & 3.09 & 3 & 27.27 \\
Alveolar cell & 6 & 2.25 & 4 & 50.00 \\
Adenocarcinoma & 5 & 1.69 & 5 & 83.33 \\
and alveolar cell & & 1.40 & 1 & 20.00 \\
Squamous & 2 & 0.56 & 1 & 50.00 \\
and large cell & & & & \\
Neuroendocrine & 2 & 0.56 & 0 & 0 \\
Adenocarcinoma & 2 & 0.56 & 0 & 0 \\
and large cell & & & & \\
Sarcomatodes & 1 & 0.28 & 0 & 0 \\
Adenoid cystic & 1 & 0.28 & 0 & 0 \\
$\begin{array}{l}\text { Poorly } \\
\text { differentiated }\end{array}$ & 89 & 25.00 & 23 & 25.84 \\
Total & 356 & 100.00 & 139 & 39.04 \\
\hline
\end{tabular}

NSCLC, non-small cell lung cancer.

Correlation between EGFR mutations and histological parameters. The overall rate of activating EGFR mutations was $39.04 \%$, with $50.87 \%(88 / 173)$ in the adenocarcinoma and $25.00 \%(14 / 56)$ in the squamous cell carcinoma samples. There was a significant difference in the $E G F R$ mutation rate between adenocarcinoma and squamous cell carcinoma $(\mathrm{P}=0.0004)$. The prevalence of activating EGFR mutation rates in other subtypes of NSCLC are summarized in Table V. It should be noted that the activating EGFR mutations often occurred in NSCLC with the adenosquamous carcinoma $(50.00 \%, 4 / 8)$ and alveolar cell carcinoma subtypes $(83.33 \%, 5 / 6)$. In addition, $25.84 \%$ (23/89) of EGFR mutations were detected in poorly differentiated NSCLC. Although the difference was
Table VI. Comparison of the activating mutation rate between males and females with adenocarcinoma.

\begin{tabular}{lcccc}
\hline & All & Wild-type & Mutation & \\
Adenocarcinoma & $\mathrm{n}(\%)$ & $\mathrm{n}(\%)$ & $\mathrm{n}(\%)$ & P-value \\
\hline Males & $84(58.99)$ & $44(55.00)$ & $38(50.32)$ & 0.1722 \\
Females & $89(41.01)$ & $36(45.00)$ & $50(49.68)$ & \\
\hline
\end{tabular}

not statistically significant, the activating EGFR mutations occurred more frequently in females compared to males with the adenocarcinoma subtype $(56.18 \%$ and $50 / 89$ vs. $45.24 \%$ and $38 / 84, \mathrm{P}=0.1722$; Table VI).

Between the smoking and non-smoking male patients with the adenocarcinoma subtype, the rate of activating EGFR mutations was similar ( 48.44 vs. $50.00 \%, \mathrm{P}=0.5814$ ). Of note, the activating EGFR mutations occurred more frequently in females compared to males with the squamous cell carcinoma subtype (40.00 vs. $23.68 \%, \mathrm{P}=0.4253$; Table VII).

Correlation between EGFR mutation status and sample type. Among all the samples analyzed, $112(31.46 \%)$ were bronchoscopic biopsies, 224 (62.93\%) were surgical resections and $20(5.61 \%)$ were pleural effusion cytological samples. The pleural effusion cytological samples were collected from patients diagnosed with NSCLC and confirmed by a pathologist to contain tumor cells. The corresponding activating EGFR mutation rates were $45.00,30.36$ and $42.86 \%$, respectively (Table VIII). It is important to note that the rate of $E G F R$ mutations identified from the bronchoscopic biopsies was lower than that from the surgical resections or pleural effusion, and was also lower than the overall rate. A statistically significant difference in the EGFR mutation rate in the bronchoscopic biopsies and surgical resections was observed $(\mathrm{P}=0.0425)$.

Detection of EGFR mutations by different methods. A total of 86 samples was successfully analyzed by PCR amplification followed by direct sequencing. Direct sequencing identified EGFR mutations in 34 (39.53\%) samples. The EGFR mutation rates in pleural effusion, bronchoscopic biopsies and surgical resections were $14.29(1 / 7), 30.00$ (3/10) and $43.47 \%$ (30/69), respectively. Although there was no statistically significant difference, EGFR mutations were more frequently identified in the surgical resections than the other two types of samples by direct sequencing.

A total of 120 samples was analyzed by ARMS assay and $43(35.83 \%)$ were identified as EGFR mutation-positive. The $E G F R$ mutation rates detected by ARMS were $55.56(5 / 9)$, $30.30(20 / 66)$ and $40.00 \%(18 / 45)$ for the individual sample types. A total of 150 samples was analyzed by HRM assay followed by sequencing verification. HRM combined with sequencing verification detected $E G F R$ mutations in $62(41.33 \%)$ of the analyzed samples. The EGFR mutation rates were $75.00(3 / 4), 30.56(11 / 36)$ and $43.64 \%(48 / 110)$ for the three sample types (Table IX). Taken together, for the tissue samples, such as bronchoscopic biopsy and surgical resection, the rate of $E G F R$ mutations detected by any of the three methods was comparable. For detecting mutations in pleural 
Table VII. Comparison of the activating mutation rate between males and females, and smokers and non-smokers.

\begin{tabular}{|c|c|c|c|c|}
\hline & \multicolumn{3}{|c|}{ Males } & \multirow[b]{2}{*}{ Females } \\
\hline & Smokers & Non-smokers & Unknown & \\
\hline \multicolumn{5}{|l|}{ Adenocarcinoma } \\
\hline Total & 64 & 15 & 5 & 89 \\
\hline Mutation & 31 & 6 & 1 & 50 \\
\hline Mutation rate $(\%)$ & 48.44 & 50.00 & 20.00 & 56.18 \\
\hline \multicolumn{5}{|c|}{ Squamous cell carcinoma } \\
\hline Total & 38 & 3 & 5 & 10 \\
\hline Mutation & 9 & 0 & 1 & 4 \\
\hline Mutation rate $(\%)$ & 23.68 & 0 & 20.00 & 40.00 \\
\hline
\end{tabular}

Table VIII. Comparison of the activating mutation rate among different sample types.

\begin{tabular}{|c|c|c|c|c|c|}
\hline & $\begin{array}{c}\text { All } \\
\text { n (\%) }\end{array}$ & $\begin{array}{c}\text { Wild-type } \\
\mathrm{n}(\%)\end{array}$ & $\begin{array}{c}\text { Mutation } \\
\mathrm{n}(\%)\end{array}$ & $\begin{array}{l}\text { Mutation } \\
\text { rate }(\%)\end{array}$ & P-value \\
\hline Pleural effusion & $20 \quad(5.61)$ & $11 \quad(5.53)$ & $(6.47)$ & 45.00 & 0.8158 \\
\hline Bronchoscopic biopsies & $112(31.46)$ & $71(35.17)$ & $34 \quad(24.46)$ & 30.36 & $0.0425^{\mathrm{a}}$ \\
\hline Surgical resections & $224(62.93)$ & $117(59.30)$ & $96 \quad(69.07)$ & 42.86 & 0.0618 \\
\hline
\end{tabular}

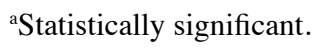

effusion, ARMS and HRM assays were possibly superior to direct sequencing. Nevertheless, it should be noted that no statistically significant difference between direct sequencing and ARMS assay $(\mathrm{P}=0.1451)$ or direct sequencing and HRM assay $(\mathrm{P}=0.0879)$ with respect to the mutation frequency was obtained due to the limited sample numbers. Regardless of the method used, the EGFR mutation rate detected in the bronchoscopic biopsies was the lowest.

Method correlation with sequencing. The EGFR mutation status of 114 samples detected by ARMS assay using the AmoyDx ${ }^{\mathrm{TM}}$ EGFR 29 Mutations Detection kit (Amoy Diagnostics Co.) was tested again by direct sequencing. We were unable to perform additional sequencing for six samples due to insufficient gDNA. Forty EGFR mutation-positive and 44 EGFR mutation-negative samples reached a consensus in the two methods (Table $\mathrm{X}$ ). The concordance rate between the two methods was $73.68 \%$.

Fifteen $E G F R$ mutation-positive samples detected by ARMS assay were found to be $E G F R$ mutation-negative by sequencing. It is important to note that another $15 E G F R$ mutation-negative samples detected by ARMS assay were found to be $E G F R$ mutation-positive by sequencing. Direct sequencing identified 11 rare mutations that were not designed to be detected by ARMS assay, including p.E709_T710del, p.G729E, p.G729V, p.L747P, p.A864E and p.E866V. A discrepancy was observed in another four samples between the two methods. The sensitivity of ARMS assay was $72.73 \%$ and the specificity $74.58 \%$.
A total of 150 samples was tested by HRM assay for the detection of mutations in EGFR exons 18-21. HRM assay detected more positive samples than sequencing and detected 97 samples as positive for mutations. Among these, 68 samples were confirmed as positive by sequencing and 29 samples were not confirmed, which were possibly false positives. Most of these are likely to be true false positives due to degraded DNA extracted from FFPE specimens. Fifty samples were detected as negatives by both methods used. Three samples that were detected as EGFR mutation-negative by HRM were detected as EGFR mutation-positive by sequencing (Table XI). The sensitivity and specificity for the samples that were suspected of having mutations by HRM assay was 95.77 and $63.29 \%$ when compared to sequencing, with an accuracy rate of $78.67 \%$. For each patient, EGFR mutation testing was carried out on the same gDNA, avoiding the inconsistency potentially resulting from intra-tumor heterogeneity. Collectively, the discordance was $26.32 \%$ between direct sequencing and ARMS and was $21.33 \%$ between direct sequencing and HRM.

Sensitivity testing by direct sequencing, ARMS and HRM. The gDNA of the PC-9 cells was serially diluted into A549 gDNA at ratios of $100,40,20,10$ and $2 \%$ to yield mutant allele frequencies of 50,20, 10, 5 and $1 \%$. The relative sensitivity of direct sequencing, ARMS and HRM was evaluated using the diluted DNA. The mutation was detectable (at a low peak) by direct sequencing when the mutant frequency was higher than $10 \%$. However, when the mutation frequency was at $5 \%$, it was only distinguishable from the background. 
Table IX. Comparison of the activating mutation rate detected by different methods in different sample types.

\begin{tabular}{|c|c|c|c|c|c|c|c|c|c|c|c|}
\hline \multicolumn{3}{|c|}{ All } & \multicolumn{3}{|c|}{ Pleural fluid } & \multicolumn{3}{|c|}{ Bronchoscopic biopsies } & \multicolumn{3}{|c|}{ Surgical resections } \\
\hline Method & Total & Rate $(\%)$ & Total & Mutation & Rate $(\%)$ & Total & Mutation & Rate (\%) & Total & Mutation & Rate $(\%)$ \\
\hline Sequencing & 86 & 39.53 & 7 & 1 & 14.29 & 10 & 3 & 30.00 & 69 & 30 & 43.47 \\
\hline ARMS & 120 & 35.83 & 9 & 5 & 55.56 & 66 & 20 & 30.30 & 45 & 18 & 40.00 \\
\hline $\mathrm{HRM}$ and $\mathrm{Se}$ & 150 & 41.33 & 4 & 3 & 75.00 & 36 & 11 & 30.56 & 110 & 48 & 43.64 \\
\hline
\end{tabular}

ARMS, amplification refractory mutation system; HRM, high resolution melting; HRM and Se, HRM and sequencing.

Table X. Comparison of the results of the EGFR mutation analysis between ARMS and direct sequencing.

\begin{tabular}{llcc}
\hline & \multicolumn{2}{c}{ Sequencing } & \\
\cline { 2 - 3 } $\begin{array}{l}\text { Mutation } \\
\text { status }\end{array}$ & + & - & Total \\
\hline ARMS & & & \\
+ & 40 & 15 & 55 \\
- & 15 & 44 & 59 \\
Total & 55 & 59 & 114 \\
\hline
\end{tabular}

$E G F R$, epidermal growth factor receptor; ARMS, amplification refractory mutation system.

Table XI. Comparison of the results of the EGFR mutation analysis between HRM and sequencing.

\begin{tabular}{lccc}
\hline & \multicolumn{2}{c}{ Sequencing } & \\
\cline { 2 - 3 } $\begin{array}{l}\text { Mutation } \\
\text { status }\end{array}$ & + & - & Total \\
\hline HRM & 68 & 29 & \\
+ & 3 & 50 & 97 \\
- & 71 & 79 & 53 \\
Total & & & 150 \\
\hline
\end{tabular}

$E G F R$, epidermal growth factor receptor; HRM, high resolution melting.

When the mutant frequency was below $5 \%$, the mutation was not detectable (Fig. 2A). ARMS assay positively detected the deletions in EGFR exon 19 in the sample containing down to $1 \%$ mutant allele frequency (Fig. 2B). Using HRM, the melting curve from $1 \%$ mutant template sufficiently differed from wild-type template (Fig. 2C), and this distinct melting profile was consistently observed across all other templates measured $(5,10,20$ and $50 \%)$. Thus, the sensitivity of direct sequencing, ARMS and HRM was found to be 10,1 and $1 \%$, respectively.

\section{Discussion}

Based on the observations from IPASS and other studies $(14,15)$, the ASCO provisional clinical opinion (PCO) states that 'patients with advanced NSCLC who are being considered for first-line therapy with an EGFR-TKI should have their tumor tested for EGFR mutations to determine which is an appropriate therapy: an EGFR-TKI or chemotherapy' $(7,16)$. Therefore, evaluating the EGFR mutation status is a matter of urgency in clinical practice, particularly in patients with adenocarcinoma.

As a matter of fact, the selection of patients for EGFR-TKI therapy based on mutation analysis is not an absolute warranty for good response and approximately $20-30 \%$ of patients harboring activating EGFR mutations do not benefit from TKI treatment (17). The presence of TKI-resistant or increased copy number (amplification) of the MET oncogene contributes to resistance to TKI. Furthermore, the low abundance of EGFR mutations affects the response to TKI (18). False positives due to the methodology used for mutation detection should not be neglected, particularly when an extremely sensitive test is performed. On the other hand, a proper interpretation of negative results requires a thorough understanding of the technical limitations of the assay and the type of specimen used for mutation detection. One of the possible reasons that patients without activating EGFR mutations respond to an EGFR-TKI is the false negatives (13). For example, as previously demonstrated, five out of 50 patients with advanced NSCLC had discrepancies in the results of mutant-enriched PCR, peptide nucleic acid-locked nucleic acid (PNA-LNA) PCR and PCR clamp. All five patients were false-negative as they responded to gefitinib (19).

In the present study, the prevalence of EGFR mutations was higher in females than in males and the frequency of activating EGFR mutations (39.04\%) was similar to that described in earlier studies conducted on patients with advanced NSCLC in an East Asian group (20). Two types of mutations, the short in-frame deletions in exon 19 (particularly p.E746_A750del) and the point mutation in exon 21 (c.2573T $>$ G, p.L858R) comprised up to $90 \%$ of mutations. This is also in line with what has been previously described $(3,4,21,22)$. Low-frequency mutations in exon 18 and exon 21 , such as p.G719X and p.L861Q, were also found. Of note, three cases carrying the complex mutations of p.L833V and p.H835L in exon 21 were detected in this study. The occurrence frequency of these types of mutation $(2.16 \%, 3 / 139)$ was equivalent to that of p.L861Q. A good response to EGFR-TKI therapy has been reported in one patient harboring the p.L833V and p.H835L mutations (23); therefore, this specific type of mutation was considered one of the activating EGFR mutations. The correlation of p.L833V and p.H835L mutations with TKI response requires further 
A

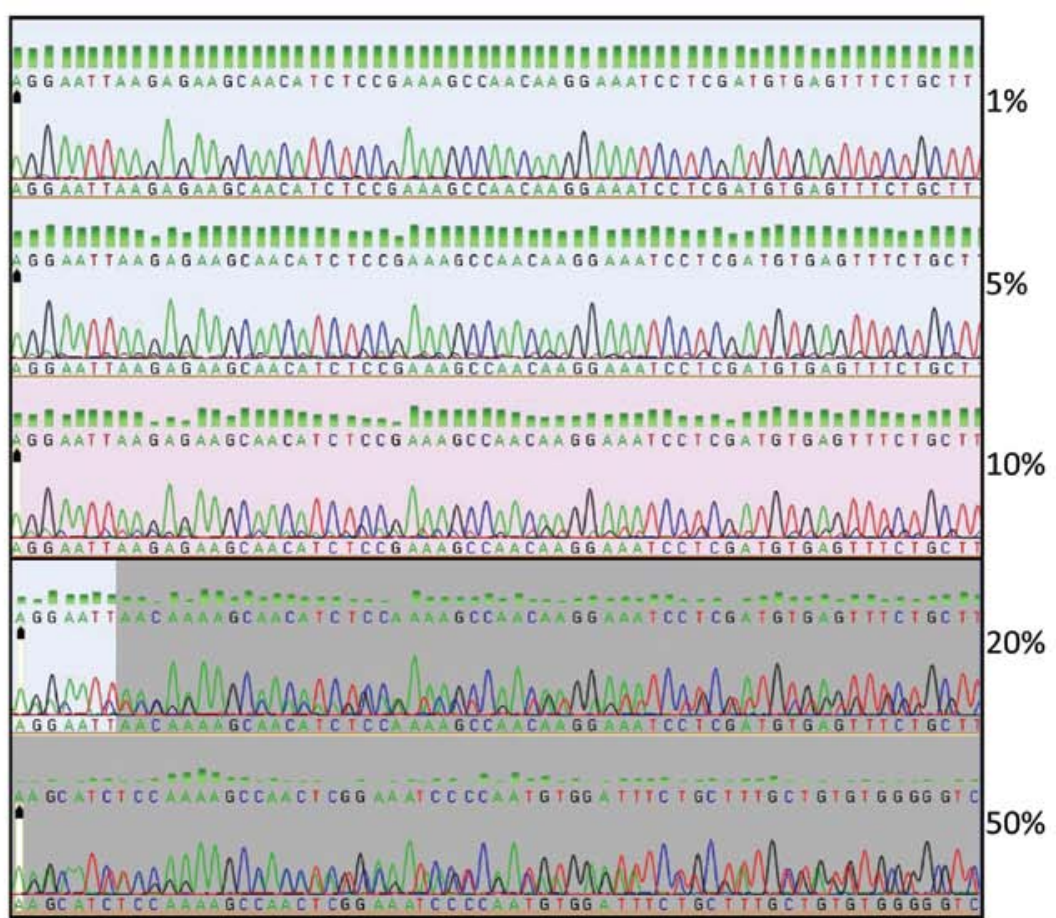

B

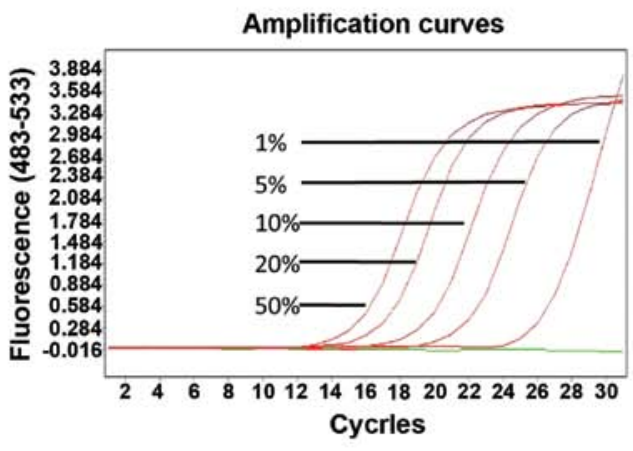

C

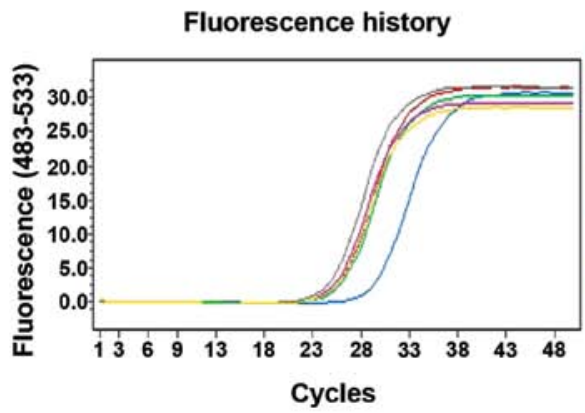

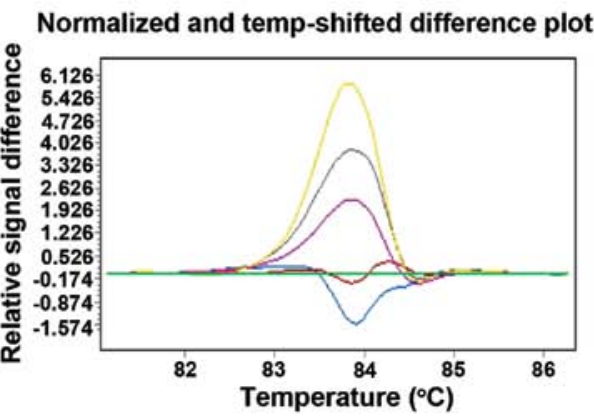

Figure 2. Sensitivity testing for epidermal growth factor receptor $(E G F R)$ mutations using serial dilutions of PC-9/A549 DNA. (A) Direct sequencing. At least $10 \%$ mutant DNA was necessary to detect EGFR mutations. (B) Amplification refractory mutation system (ARMS). One percent mutant DNA was ready to be indentified from wild-type DNA. (C) High resolution melting (HRM). $1 \%$ mutant DNA was ready to be plotted differently from wild-type DNA.

clinical investigation. In addition, 13 mutations that were not associated with TKI response were detected in treatment-free samples.

All the females with advanced NSCLC in this study were non-smokers and the EGFR mutation rate was significantly higher in the non-smokers than in the smokers, which is in line with previous studies reporting that EGFR mutations were more frequently detected in patients without a smoking history $(5,15)$. A recent meta-analysis demonstrated that non-smokers with NSCLC show a statistically significant increase in the prevalence of somatic EGFR mutations (20). The activating EGFR mutations were more often detected in patients with adenocarcinoma than in patients with squamous cell carcinoma. Among the adenocarcinoma patients, the prevalence of activating EGFR mutations was modestly higher in females than in males; however, this difference was not statistically significant. Importantly, among the male patients with adenocarcinoma, no difference was observed in the muta- 
tion rate between smokers and non-smokers. Almost all the male patients diagnosed with squamous cell carcinoma were smokers, and the frequency of activating EGFR mutations was much higher in the females (non-smokers) than in the male smokers. Only three males with squamous cell carcinoma were non-smokers and were unable to be analyzed statistically. Thus, we suggest that adenocarcinoma, particularly in females, is a valuable predictive factor for the occurrence of $E G F R$ mutations. A smoking history largely affected the $E G F R$ mutation occurrence in patients with squamous cell carcinoma rather than adenocarcinoma.

In order to carry out a routine EGFR mutation screening in clinical practice, good quality DNA in sufficient quantity, including tumor content (particularly for cytological material), and the most reliable method in terms of sensitivity and specificity are an absolute requirement. Resected tumor tissues are preferred, but they are not always available. Small biopsy samples and cytological material, including that obtained from pleural effusion, are increasingly used in clinical practice. In the present study, three types of samples, i.e., surgical resections, bronchoscopic biopsies and pleural effusion, were tested for $E G F R$ mutations. We found that the lowest frequency of activating EGFR mutations was observed in the bronchoscopic biopsies (30.36\%). In clinical practice, it is not possible to obtain both bronchoscopic biopsies and surgical sections from the same patient. In the present study, the bronchoscopic biopsies are obtained from advanced NSCLC patients with unresectable tumors, while the surgical sections were obtained from NSCLC patients, at early clinical stage, who had received surgical therapy. However, the clinical features, including pathological type and gender (data not shown), that significantly affected the EGFR mutation frequency in the sample sets from the bronchoscopic biopsies and surgical sections were comparable. The mutation rate in pleural effusion $(45.00 \%)$ was similar to that in surgical resections (42.86\%; Table VIII). Our observations are in accordance with those from previous studies on the detection of EGFR mutations in cytological samples $(5,24)$. Five methods, including PCR-Invader, PNA-LNA PCR clamp, direct sequencing, cycleave PCR and ARMS, show a comparable performance in the assessment of tissue and cytology samples. Cytology-derived DNA is a suitable alternative to FFPE samples and very useful when FFPE samples are unavailable for molecular analysis $(5,24)$.

Multiple sensitive techniques are employed as alternatives to direct sequencing. Using cell lines with heterozygous $E G F R$ mutations, we found that the sensitivities of direct sequencing, ARMS and HRM in our experimental setting were 10, 1 and $1 \%$, respectively. The overall mutation rate detected by ARMS assay was the lowest $(35.83 \%)$, and the mutation rate detected by direct sequencing (39.53\%) was similar to that detected by HRM assay (41.33\%; Table IX). The clinical characteristics of the samples tested by the three methods, which significantly affected the EGFR mutation frequency, including pathological type and gender (data not shown), were comparable. In the 224 surgical resections, the difference observed in the mutation rates $(43.47,40.00$ and $43.64 \%)$ detected by the three methods (sequencing, ARMS, and HRM and sequencing together, respectively) was not considerable. In the 112 bronchoscopic biopsies, the mutation rates detected by the three methods (30.00, 30.30 and 30.56\%) were almost the same and clearly lower than those detected in surgical resections. In the 20 pleural effusion samples, the mutation rate detected by direct sequencing was the lowest (14.29\%), and the mutation rates detected by ARMS (55.56\%) and HRM assay (75.00\%) were even higher than the average rate of all samples $(39.04 \%)$ (Table IX). Collectively, sensitive methods, i.e., ARMS and HRM, were not superior to direct sequencing in surgical resections and bronchoscopic biopsies in terms of mutation detection frequency in this study. The possible reasons for this were the quantity control of tumor content $(>20 \%)$ in FFPE sections by H\&E staining and improved sensitivity (10\%) of direct sequencing by optimizing all reaction conditions. It is also important to note that the prevalence of EGFR mutations detected in bronchoscopic biopsies using any of the three methods was the lowest. Bronchoscopic biopsies usually contain smaller amounts of tissue than surgical resections due to the limited tissue size; they also provide relatively inadequate information a molecular evaluation due to tumor heterogeneity. The amount of DNA extracted from small biopsy specimens varies significantly, depending on the size of the material, the tumor viability, etc. The minimum amount of DNA extracted from FFPE samples for direct sequencing, ARMS and HRM assay are 300, 100 and $150 \mathrm{ng}$, respectively. Therefore, ARMS assay is preferred when the sample DNA is extremely low $(4,13)$.

In addition, it was necessary to detect EGFR mutations in pleural effusion, using a sensitive technique, such as ARMS or HRM. The findings of the present study were consistent with those of several other studies. ARMS assay is more sensitive in detecting EGFR mutations than direct sequencing in cytological samples from transbronchial needle aspirates or pleural effusion $(25,26)$. Other methods, including pyrosequencing and HRM, have been reported (27,28). A recent review evaluating 33 studies using cytological samples for EGFR mutation testing suggested that the use of sensitive methods is warranted when cytological samples with low-tumor content are used (5).

In the present study, EGFR mutations were identified in the same gDNA using two methods with low and high sensitivity concomitantly. The concordance rate between direct sequencing and ARMS assay was $73.68 \%$. The discordance found in the mutation status in direct sequencing and ARMS may be explained by the different degree of of sensitivity, particularly for identifying a low abundance of mutations. A total of 11 (out of 15) mutations detected by direct sequencing were not detected by ARMS, as the ARMS assay used was not designed to detect these rare EGFR mutations. Clinical data on less common mutations are being increasingly gathered. However, further research on the analysis of predictable outcomes on TKI response is required $(23,29)$. An analysis of another four mutations, which were detected only via direct sequencing, was not carried out using ARMS due to insufficient materials. The observations of the present study were in accordance with those of other studies that compare direct sequencing with ARMS. Compared with direct sequencing, 10-20\% of mutations are missed by ARMS, but $20 \%$ of mutations detected by ARMS at low levels are missed by direct sequencing $(8,30,31)$. In another study, $32 \%$ of tumors carrying activating EGFR mutations detected by direct sequencing are missed by the commercially available ARMS kit. The percentage of missed mutations is too 
high to recommend the use of ARMS for diagnostic application (32).

The sensitivity of HRM in the present study was $95.77 \%$, which is similar to that found in other studies $(10,33,34)$. The concordance rate between HRM and sequencing was $78.67 \%$. The difference in sensitivity was one of the reasons for the discrepancy. In addition, any DNA alteration due to the interference of single nucleotide polymorphism (SNP) or formalin fixation may produce an abnormal melting curve (35). The high rate of false positives in FFPE samples indicates that an additional sequencing should be performed.

Given the respective limitations of the currently available testing methodologies, several laboratories tend to use a combination of methodologies $(5,30)$. In a previous study, we also proposed a sequential detection workflow using ARMS assay and/or direct sequencing (13). Thus, each method compensates for the disadvantages of the other and reduces the frequency of false negatives.

In conclusion, we recommend that the choice of method should be made based on the sample type. An analysis of samples obtained at the diagnostic stage, e.g., bronchoscopic biopsies, should be performed using the ARMS assay for the detection of mutations due to the limited amount of DNA extracted from small biopsy specimens. A sensitive method, such as ARMS, is necessary when mutations in cytological samples, such as those obtained from pleural effusion, need to be detected. The choice of method used for mutation detection in samples from surgical resections is largely based on the expertise of the laboratory, but direct sequencing is highly recommended. However, the low detection rate of $E G F R$ mutations by direct sequencing is possibly due to limited sensitivity. The absence of EGFR mutations, determined by methods that detect known mutations, such as ARMS, cannot be the exclusion criterion for EGFR-TKI usage. Therefore, we suggest performing two methods (direct sequencing and a sensitive method) sequentially in clinical practice, due to the presence of non-neglected discordance between any method from its own benefits and drawbacks. In the future, we may be able to benefit from the incorporation of next-generation sequencing into daily clinical practice.

\section{Acknowledgements}

The present study was supported by the Jiangsu Provincial Natural Science Foundation of China (grant no. BK2011306) and the National Natural Science Foundation of China (grant no. 81172433).

\section{References}

1. Lynch TJ, Bell DW, Sordella R, et al: Activating mutations in the epidermal growth factor receptor underlying responsiveness of non-small-cell lung cancer to gefitinib. N Engl J Med 350: 2129-2139, 2004.

2. Paez JG, Jänne PA, Lee JC, et al: EGFR mutations in lung cancer: correlation with clinical response to gefitinib therapy. Science 304: 1497-1500, 2004.

3. Sharma SV, Bell DW, Settleman J and Haber DA: Epidermal growth factor receptor mutations in lung cancer. Nat Rev Cancer 7: 169-181, 2007.

4. Lopez-Rios F, Angulo B, Gomez B, et al: Comparison of molecular testing methods for the detection of EGFR mutations in formalin-fixed paraffin-embedded tissue specimens of non-small cell lung cancer. J Clin Pathol, 66: 381-385, 2013.
5. Ellison G, Zhu G, Moulis A, Dearden S, Speake G and McCormack R: EGFR mutation testing in lung cancer: a review of available methods and their use for analysis of tumour tissue and cytology samples. J Clin Pathol 66: 79-89, 2013.

6. Pirker R, Herth FJ, Kerr KM, et al: Consensus for EGFR mutation testing in non-small cell lung cancer: results from a European workshop. J Thorac Oncol 5: 1706-1713, 2010.

7. Beasley MB and Milton DT: ASCO provisional clinical opinion: epidermal growth factor receptor mutation testing in practice. J Oncol Pract 7: 202-204, 2011.

8. Ellison G, Donald E, McWalter G, et al: A comparison of ARMS and DNA sequencing for mutation analysis in clinical biopsy samples. J Exp Clin Cancer Res 29: 132, 2010.

9. Wittwer CT: High-resolution DNA melting analysis: advancements and limitations. Hum Mutat 30: 857-859, 2009.

10. Do H, Krypuy M, Mitchell PL, Fox SB and Dobrovic A: High resolution melting analysis for rapid and sensitive EGFR and KRAS mutation detection in formalin fixed paraffin embedded biopsies. BMC Cancer 8: 142, 2008.

11. Krypuy M, Newnham GM, Thomas DM, Conron M and Dobrovic A: High resolution melting analysis for the rapid and sensitive detection of mutations in clinical samples: KRAS codon 12 and 13 mutations in non-small cell lung cancer. BMC Cancer 6: 295, 2006.

12. Fukuoka M, Wu YL, Thongprasert S, et al: Biomarker analyses and final overall survival results from a phase III, randomized, open-label, first-line study of gefitinib versus carboplatin/paclitaxel in clinically selected patients with advanced non-small-cell lung cancer in Asia (IPASS). J Clin Oncol 29: 2866-2874, 2011.

13. Zhuang Y, Xu J, Ma H, et al: A sequential method of epidermal growth factor receptor mutation detection reduces false negatives: a new case with doublet mutations of L833V and H835L in China. Clin Lung Cancer 14: 295-300, 2013.

14. Mok TS, Wu YL, Thongprasert S, et al: Gefitinib or carboplatinpaclitaxel in pulmonary adenocarcinoma. N Engl J Med 361: 947-957, 2009

15. Douillard JY, Shepherd FA, Hirsh V, et al: Molecular predictors of outcome with gefitinib and docetaxel in previously treated non-small-cell lung cancer: data from the randomized phase III INTEREST trial. J Clin Oncol 28: 744-752, 2010.

16. Keedy VL, Temin S, Somerfield MR, et al: American society of clinical oncology provisional clinical opinion: epidermal growth factor receptor (EGFR) mutation testing for patients with advanced non-small-cell lung cancer considering first-line EGFR tyrosine kinase inhibitor therapy. J Clin Oncol 29: 2121-2127, 2011.

17. Gazdar AF: Tyrosine kinase inhibitors and epidermal growth factor receptor (EGFR) mutations in non-small cell lung cancer: to test or not to test? Medicine (Baltimore) 90: 168-170, 2011.

18. Zhou Q, Zhang XC, Chen ZH, et al: Relative abundance of EGFR mutations predicts benefit from gefitinib treatment for advanced non-small-cell lung cancer. J Clin Oncol 29: 3316-3321, 2011.

19. Ikeda T, Nakamura Y, Yamaguchi H, et al: Direct comparison of 3 PCR methods in detecting EGFR mutations in patients with advanced non-small-cell lung cancer. Clin Lung Cancer 13: 369-74 2012.

20. Ren JH, He WS, Yan GL, Jin M, Yang KY and Wu G: EGFR mutations in non-small-cell lung cancer among smokers and non-smokers: a meta-analysis. Environ Mol Mutagen 53: 78-82, 2012.

21. Angulo B, Conde E, Suarez-Gauthier A, et al: A comparison of EGFR mutation testing methods in lung carcinoma: direct sequencing, real-time PCR and immunohistochemistry. PLoS One 7: e43842, 2012.

22. Liang Z, Zhang J, Zeng X, Gao J, Wu S and Liu T: Relationship between EGFR expression, copy number and mutation in lung adenocarcinomas. BMC Cancer 10: 376, 2010.

23. Yang TY, Tsai CR, Chen KC, Hsu KH, Lee HM and Chang GC: Good response to gefitinib in a lung adenocarcinoma harboring a heterozygous complex mutation of $\mathrm{L} 833 \mathrm{~V}$ and $\mathrm{H} 835 \mathrm{~L}$ in epidermal growth factor receptor gene. J Clin Oncol 29: e468-e469, 2011.

24. Goto K, Satouchi M, Ishii G, et al: An evaluation study of EGFR mutation tests utilized for non-small-cell lung cancer in the diagnostic setting. Ann Oncol 23: 2914-2919, 2012.

25. Horiike A, Kimura H, Nishio K, et al: Detection of epidermal growth factor receptor mutation in transbronchial needle aspirates of non-small cell lung cancer. Chest 131: 1628-1634, 2007. 
26. Kimura H, Fujiwara Y, Sone T, et al: High sensitivity detection of epidermal growth factor receptor mutations in the pleural effusion of non-small cell lung cancer patients. Cancer Sci 97: 642-648, 2006.

27. Kim HJ, Oh SY, Kim WS, et al: Clinical investigation of EGFR mutation detection by pyrosequencing in lung cancer patients. Oncol Lett 5: 271-276, 2013.

28. Fassina A, Gazziero A, Zardo D, Corradin M, Aldighieri E and Rossi GP: Detection of EGFR and KRAS mutations on trans-thoracic needle aspiration of lung nodules by high resolution melting analysis. J Clin Pathol 62: 1096-1102, 2009.

29. He M, Capelletti M, Nafa K, et al: EGFR exon 19 insertions: a new family of sensitizing EGFR mutations in lung adenocarcinoma. Clin Cancer Res 18: 1790-1797, 2012.

30. Leary AF, Castro DG, Nicholson AG, et al: Establishing an EGFR mutation screening service for non-small cell lung cancer-sample quality criteria and candidate histological predictors. Eur J Cancer 48: 61-67, 2012.

31. Liu Y, Liu B, Li XY, et al: A comparison of ARMS and direct sequencing for EGFR mutation analysis and tyrosine kinase inhibitors treatment prediction in body fluid samples of non-smal-cell lung cancer patients. J Exp Clin Cancer Res 30: $111,2011$.
32. Penzel R, Sers C, Chen Y, et al: EGFR mutation detection in NSCLC-assessment of diagnostic application and recommendations of the German panel for mutation testing in NSCLC. Virchows Arch 458: 95-98, 2011.

33. Takano T, Ohe Y, Tsuta K, et al: Epidermal growth factor receptor mutation detection using high-resolution melting analysis predicts outcomes in patients with advanced non-small cell lung cancer treated with gefitinib. Clin Cancer Res 13: 5385-5390, 2007.

34. Gonzalez-Bosquet J, Calcei J, Wei JS, et al: Detection of somatic mutations by high-resolution DNA melting (HRM) analysis in multiple cancers. PLoS One 6: e14522, 2011.

35. Franklin WA, Haney J, Sugita M, Bemis L, Jimeno A and Messersmith WA: KRAS mutation: comparison of testing methods and tissue sampling techniques in colon cancer. $\mathrm{J}$ Mol Diagn 12: 43-50, 2010. 